\title{
Refractive Errors and Low Vision Rehabilitation in Patients with Oculocutaneous Albinism
}

\author{
Deniz Altınbay ${ }^{1}$ \\ ${ }^{1}$ Private NIV Eye Center, Adana, Turkey
}

\begin{abstract}
Purpose: To evaluate the types of refractive errors in patients of Oculocutaneous Albinism and find their compliance (OCA) to low vision aids.
\end{abstract}

Study Design: Descriptive observational study.

Place and Duration of Study: Provincial Directorate of Health, Adana City Education and Research Hospital, from 2010 to 2018.

Methods: Seven hundred and fifteen patients attended the hospital between 2010 and 2018 with the complaint of low vision and 31 patients with OCA were included in this study by convenient sampling. Best corrected distance and near visual acuity (VA) was measured along with the complete ocular examination. Patients were classified according to low vision and refraction degrees. High degree near eyeglasses, Galilean and Keplerian telescopes, magnifiers and special filter glasses were used as low vision aids (LVA).

Results: Mean age was $16.45 \pm 12.72$ years. On admission, mean distance VA was $0.12 \pm 0.07$ [mean log MAR 0.9 ], near VA was $1.48 \mathrm{M} \pm 0.74 \mathrm{M}$, astigmatism was $4.02 \pm 1.45$ diopters (D), and spherical equivalents were 1.54 \pm 4.96 D. Hypermetropia was seen more frequently than myopia. Twenty-seven (87\%) patients were prescribed telescopes for distance. Near visual acuity increased from $1.4 \mathrm{M} \pm 0.7 \mathrm{M}$ to $0.9 \mathrm{M} \pm 0.4 \mathrm{M}$ after rehabilitation. There was an increase in distance visual acuity in all patients $(p<0.001)$. Seventeen $(63 \%)$ patients bought the telescope, and 15 (55\%) patients used the device. The most preferred special filter glasses were $450 \mathrm{~nm}(39 \%)$ and $540 \mathrm{~nm}(25 \%)$.

Conclusion: Astigmatism in oculocutaneous albinism was with the rule and the most commonly detected refractive error was hypermetropia. Patients are non-compliant in buying telescopes in which case tablet and computers with special applications for low vision can be better options.

Key Words: Albinism, Low vision, Low vision rehabilitation, Refraction, Refractive errors.

How to Cite this Article: Altinbay D. Refractive Errors and Low Vision Rehabilitation in Patients with Oculocutaneous Albinism, Pak J Ophthalmol. 2020, 36 (2): 150-155.

Doi: $10.36351 /$ pjo.v36i2.978

Correspondence: Deniz Altınbay

Private NIV Eye Center, Adana/Turkey

Email: denizaltinbay01@gmail.com

Received: January 2, 2020

Accepted: March 6, 2020

\section{INTRODUCTION}

Albinism is a congenital, genetic, heterogeneous disease characterized by the defect in the synthesis of melanin pigment that gives color to skin, hair, and eyes. Approximately, one out of 17000 people is affected by albinism. It is the condition of absence or lack of melanin pigment. Ocular Albinism (OA) is the type of albinism which only affects the eye; 
oculocutaneous albinism (OCA) is the type of albinism that affects eye, hair, and skin. The clinical picture varies depending on the presence or absence of tyrosinase. Nystagmus, photophobia, iris transillumination, foveal hypoplasia, high degree refractive errors and decreased visual acuity are seen as clinical presentations. ${ }^{1-3}$

This group of patients responds well to assistive devices and filters for low vision. There is a significant improvement in functional visual acuity in albinism patients with low vision rehabilitation methods such as proper light conditions and use of telescopic optical devices. ${ }^{3-5}$ It was aimed in this study to evaluate low vision rehabilitation methods and their outcomes in patients with Oculocutaneous Albinism (OCA).

\section{METHODS}

Records of 715 patients who were admitted with low vision between 2010 and 2018 in our department were retrieved and 31 patients with oculocutaneous albinism were included in the study. All procedures performed in this study were in accordance with the ethical standards of the institutional and national research committee [Provincial Directorate of Health Adana City Education and Research Hospital - 13 February 2019/number of decision: 372) and with the 1964 Helsinki declaration and its later amendments or comparable ethical standards.

Visual acuity, refraction, Biomicroscopic examination, intra ocular pressures and fundoscopic examination were performed. Cycloplegic retinoscopy was performed. Distance visual acuities (VA) were measured with distance acuity chart for low vision individuals (Test Charts for Low Vision Patients, ZEISS, Germany) and then refractive errors were corrected. The visual impairment of patients was divided into three groups, according to the WHO-ICD10 classification; moderate vision impairment $(<0.3$ and $\geq 0.1)$, severe visual impairment $(<0.1$ and $\geq 0.05)$ and blindness $(<0.05$ and $\geq 0.02) .{ }^{6}$ Degrees of Myopia and hyperopia were also grouped as low, medium and high. Near visual acuity was measured by MNREAD acuity chart (Idil SA et al). ${ }^{7}$ Patients read the reading chart from a distance at which they could see most clearly. Near vision correction for age was performed in patients over 40 years. Consequently, the magnification power and the reading distance required were calculated.

Low vision aids (LVA), such as high degree near eyeglasses, Galilean and Keplerian telescopes, sphere magnifiers and special filter glasses were used. All patients were included in the visual rehabilitation program. In this program, patients were given training on using telescopic glasses, adjusting distance in close reading, using a magnifying glass, using a digital magnifying glass and reading exercises at different points according to the point size they saw in the slow reading speed. The statistical analysis of the data was analyzed with IBM SPSS Statistics Version 20.0 package program. Categorical variables were expressed as number and percentage, and numerical variables were presented as mean and standard deviation. The chi-square test was used to compare categorical variables between groups. Fisher's Exact test result was given where the number was insufficient. Shapiro Wilk test was used to determine whether the numerical variables have a normal distribution or not. The Mann Whitney U test was used to compare the abnormally distributed numerical variables between the two groups. The Wilcoxon Signed Rank test was used to compare LVA values before and after the procedure. The level of statistical significance was set at $\mathrm{p}<0.05$.

\section{RESULTS}

Thirty-one $(4.3 \%)$ patients had oculocutaneous albinism. Sixteen $(51 \%)$ were male, and $15(48 \%)$ were female, with mean age of $16.45 \pm 12.72$. Their ages ranged from 5 to 58 years. When two patients with 47 and 58 years of age were removed, all patients were under 40 years of age. $25(80 \%)$ patients were under the age of 23 , indicating that they were in the education period. Distance visual acuity of three patients who did not attend school was evaluated with Snellen E-test chart and near visual acuities were measured in points in Times New Roman with different characters, and in terms of " $M$ " equivalent in MNREAD reading acuity chart.

The mean distance visual acuity was $0.12 \pm 0.07$ $(0.02-0.32)$ [mean log MAR 0.9], and the mean near visual acuity was $1.4 \mathrm{M} \pm 0.7 \mathrm{M}(4 \mathrm{M}-0.6 \mathrm{M})$. The mean astigmatism was $4.1 \pm 1.5$ diopter $(1.50-6.25)$, and all astigmatism patients were in accordance with the rule. Astigmatism in all patients was higher than 1.50 D. When the spherical equivalents were calculated, it was $1.54 \pm 4.96$ diopters (between -0.75 and +11.00). Twenty-one $(67.7 \%)$ patients had hypermetropia, and $10(32.2 \%)$ had myopia. Hypermetropia was seen more frequently than myopia. 
Twenty (64\%) patients had hypermetropia greater than 1.50 diopter. Only one patient's hypermetropia was lower than 1.50 diopter. Myopia was present in 10 (32.2\%) patients. $3(9 \%)$ had low (-4.00 and less), 4 $(12 \%)$ had moderate (-4.00 and -6.00$)$ and $3(9 \%)$ had high (-6.00 and above) myopia.

Keplerian Telescope (58\%) and Galilean Telescope $(36 \%)$ were recommended to 18 patients. LVA improved the visual acuity at least two log MAR line (from a decimal to a logarithmic system) in all patients. The distance visual acuity improved from $0.12 \pm 0.07$ to $0.56 \pm 0.37$ with low vision rehabilitation. There was an increase in distance visual acuity in all patients $(\mathrm{p}<0.001)$ (Figure 1).

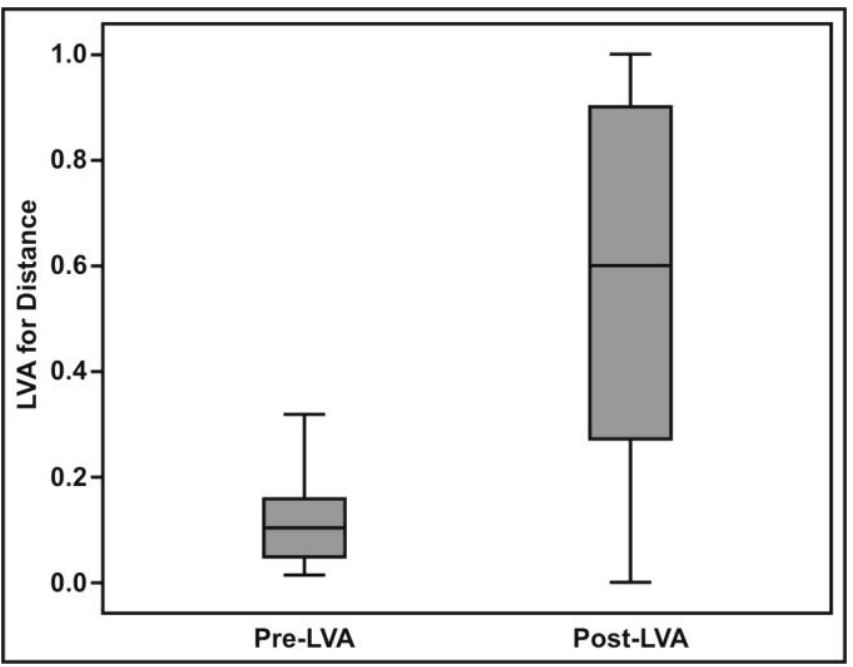

Fig. 1: Increase in visual acuity after the low vision rehabilitation.

Near visual acuity increased from $1.4 \mathrm{M} \pm 0.7 \mathrm{M}$ to $0.9 \mathrm{M} \pm 0.4 \mathrm{M}$ after rehabilitation. The ratio of patients who could read a newspaper after near rehabilitation increased from $42 \%$ to $98 \%$.

Telescope was prescribed to 27 (87\%) patients. Seventeen $(54 \%)$ patients were prescribed Keplerian telescope, and $10(32 \%)$ were prescribed a Galilean telescope. Only $62 \%$ patients purchased telescopic glasses. $88 \%$ of the patients who purchased the telescopic glasses used them. In total, $55 \%$ of patients used telescopic glasses.

For near vision correction, 39\% had VA $(1.0 \mathrm{M}$ and less) which enabled them to read newspaper points, $77 \%$ had near VA (1.6 M and less) which enabled them to read journal points without the assistance of a device.

The most preferred special filter glasses were
$450 \mathrm{~nm}(39 \%)$ and $540 \mathrm{~nm}(25 \%)$. Eleven patients preferred $450 \mathrm{~nm}$, seven patients preferred $540 \mathrm{~nm}$, three patients preferred $480 \mathrm{~nm}$, three patients preferred $500 \mathrm{~nm}$, three patients preferred $550 \mathrm{~nm}$ and one patient preferred $600 \mathrm{~nm}$. Three patients did not want a special filter glass.

In the group with poor VA before the low vision rehabilitation, it was found that the number of the telescopes purchased or purchased but then not used was few. However, it was statistically insignificant $(\mathrm{p}=0.213)$. Eleven $(61 \%)$ patients with severe visual impairment-blindness group and $5(39 \%)$ patients in the moderate visual impairment group did not use telescopes (Table 1) There was no significant relationship between the degree of refractive error and the use of telescopic glasses $(\mathrm{p}=0.349)$ (Table 1).

Table 1: Some features of patients according to the use of telescopic glasses.

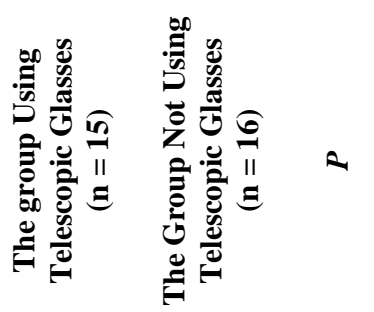

\begin{tabular}{lccc}
\hline Age & & & \\
$0-22$ & $12(\% 50)$ & $12(\% 50)$ & \\
$23-40$ & $2(\% 40)$ & $3(\% 60)$ & 0.919 \\
$40+$ & $1(\% 50)$ & $1(\% 50)$ & \\
Gender & & & \\
Male & $8(\% 50)$ & $8(\% 50)$ & 0.853 \\
Female & $7(\% 47)$ & $8(\% 53)$ & \\
Visual acuity & & & \\
Moderate visual impairment & $8(\% 61)$ & $5(\% 39)$ & 0.213 \\
Severe visual impairment \& & $7(\% 39)$ & $11(\% 61)$ & \\
blindness & & & \\
Telescopic system & & & \\
$\begin{array}{l}\text { Galileo system } \\
\text { Kepler system }\end{array}$ & $6(\% 55)$ & $5(\% 45)$ & \\
Degree of refractive error & $9(\% 50)$ & $9(\% 50)$ & \\
Low myopia/ hypermetropia & $1(\% 25)$ & $3(\% 75)$ & \\
$\begin{array}{l}\text { Medium myopia/ hypermetropia } \\
\text { High myopia/ hypermetropia }\end{array}$ & $11(\% 75)$ & $1(\% 25)$ & 0.349 \\
\hline
\end{tabular}

\section{DISCUSSION}

Patients with albinism usually present with photophobia, high refractive errors and decreased visual acuity. ${ }^{1,2,8}$ Therefore, this group of patients has more difficulty in their school life than their peers, and 
they use low vision units at an early age in order to find solutions to these problems. ${ }^{9}$ In our study, $80 \%$ of patients with oculocutaneous albinism who presented to low vision unit were in their study years of life. In a study of 120 oculocutaneous albinism patients using low vision devices, the distance VA was found between $0.98 \log$ MAR and $0.77 \log$ MAR. ${ }^{10}$ In another study of 50 eyes of 25 patients with oculocutaneous albinism, distance visual acuity was found to be $1.24 \pm 0.50 \log$ MAR. ${ }^{9}$ Eballe AO et al reported moderate visual impairment $(0.48<$ VA $\leq 1.00 \log$ MAR) in $70 \%$ of patients. ${ }^{11}$ Twenty five patients of albinism were reported in another study with 7 ocular albinism and 18 oculocutaneous albinism, the mean visual acuity was $0.9 \log$ MAR. ${ }^{12}$ Yaman et al measured visual acuity with Teller acuity cards and Snellen and found visual acuity of 0.1 or less in $62.5 \%$ of eyes. ${ }^{13}$ The visual acuity was $\log$ MAR 0.5 and above in all patients in our study.

Albinism is a heterogeneous group of diseases. Some studies included all albinism patients, some included only ocular albinism, and others included complete ocular albinism. The ages also vary. Therefore, there is no complete correlation among the studies. However, the reduction in visual acuity is emphasized in all articles. Patients in this particular study with vision of $\log$ MAR 0.5 or less could be due to the fact that the patients in our study were selected among patients who were admitted to the low vision unit.

When refractive errors were analyzed, it was observed that there were studies showing that hypermetropia was more frequent; other studies showed that myopia was more frequent while few others reported equal prevalence of both refractive errors. Hypermetropia was more frequent in studies by Wildsoet et al. and Loshin et al. ${ }^{12,14}$ In these two studies, with the rule astigmatism was seen in all patients. In the cases of Loshin et al, the astigmatic value ranged from $0.75 \mathrm{D}$ to $5.5 \mathrm{D}$, and $44.8 \%$ had astigmatism of 1D or more. ${ }^{14}$ In our study, hypermetropia was detected in $67.7 \%$ of the cases, and myopia was detected in $32.2 \%$ of the cases. With the rule astigmatism was seen in all our patients. Value of astigmatism ranged between 1.50 and 6.25 , and all were above $1.5 \mathrm{D}$.

In another study with 120 oculocutaneous albinism patients, an improvement in visual acuity was detected in mild and moderate myopia, but this improvement was mild with hyperopia above $+1.50 \mathrm{D}$. With-the-rule astigmatism was found in $37.5 \%$ of cases, $3.8 \%$ of the cases were against-the-rule astigmatism. Forty seven percent of patients with astigmatism had less than 1.50 $\mathrm{D}$ of astigmatism. An increase of 2 lines or more was seen in $48 \%$ of patients with astigmatism of $1.50 \mathrm{D}$ or more on any axis. In the current study, hypermetropia was present in $67.7 \%$ of the patients and $95 \%$ of hypermetropia patients were above $1.50 \mathrm{D}$. All astigmatism patients were above $1.50 \mathrm{D}$. There was no statistically significant relationship between improvement in visual acuity and degree of refractive error. It could be because of limited number of cases in our series.

In the study by Khanal et al, myopic astigmatism was most frequent (34\%) and spherical equivalent was found to be between $-1.59 \pm 5.39 \mathrm{D} .^{9}$

The patients with albinism have been reported to have weakness in accommodation. ${ }^{15}$ However, in albinism patients, it is reported that distant vision is a bigger problem than near vision, half of the patients can read the newspaper font without additional magnifications, as the age increases, so do the need for near glasses increases. ${ }^{16}$

In our study, we did not consider patients' accommodation capacity but the reason of better near visual acuity of our patients was the fact that $93 \%$ of the patients were under 40 years of age, and even if it was slightly weakened, it was due to their age.

In this study, approximately half of the patients who were prescribed did not use the prescribed devices. There was no statistically significant relationship between refractive error and low vision, and purchasing and using telescopic glasses. Patients did not want to use them due to economic and cosmetic reasons. In 2002, a study reported that only $50 \%$ of the visually impaired students used assistive devices and only $51 \%$ of teachers were assisting their students in using assistive technology. ${ }^{17}$

In recent years, tablets (iPad, Apple Inc, Cupertino, CA), which have special programs for low vision, have started to replace telescopic glasses in aid and rehabilitation for low vision individuals. In a randomized controlled study, young patients with low vision using classic low vision assistive devices and using iPad were compared, it was found that $90 \%$ of patients using iPad reported using their tablets at least once a day and found it easier. ${ }^{18}$

In patients with albinism, filters make things easier in their daily life. ${ }^{9}$ As it is known, blue color in 
daylight causes a lot of scattering due to a short wavelength and causes glare and contrast loss. ${ }^{19}$ Special filter glasses filter short wavelengths, increase contrast and reduce glare. ${ }^{20,21}$ In an analysis of low vision individuals consisting of 15 adults and 80 children, all reported subjective improvement in photophobia, eye fatigue, and eye discomfort when using special filter glass. In this study, it was concluded that color filters might contribute to the rehabilitation of patients with low vision. ${ }^{22}$

Sensitivity to light and low vision affect the educational processes of individuals with albinism in a negative way. Especially the difficulty in seeing the board and the difficulty in reading textbooks are important problems. ${ }^{9}$ Low vision rehabilitation techniques such as light modification and telescopic optical devices have been reported to have significant improvement in functional visual acuity in albinism patients. $^{1,3}$

The limitation of our study was that it was a retrospective data from patients less than 40 years. We did not measure the accommodation in the patients of albinism.

\section{CONCLUSION}

Astigmatism in oculocutaneous albinism was with the rule and the most commonly detected refractive error was hypermetropia. Patients are non-compliant in buying telescopes in which case tablet and computers with special applications for low vision can be better options in this young population.

\section{Ethical Approval}

The study was approved by the Institutional review board/Ethical review board.

\section{Conflict of Interest}

Authors declared no conflict of interest

\section{REFERENCES}

1. Grønskov K, Ek J, Brondum-Nielsen $\mathbf{K}$. Oculocutaneous albinism. Orphanet J Rare Dis. 2007; 2: 43 .

2. Summers CG. Albinism: classification, clinical characteristics, and recent findings. Optom Vis Sci. 2009; 86: 659-662.
3. Sowka J, Gurwood A. Low vision rehabilitation of the albino patient. Optometry, 1991; 62: 533-536.

4. Tunay ZÖ, Çalışkan D, İdil A, Öztuna D. Clinical characteristics and low vision rehabilitation methods for partially sighted school-age children. Turk J Ophthalmol. 2016; 46: 68.

5. Hoeft W. Albinism--a clinician's low vision perspective. Optometry, 1991; 62: 69-72.

6. World Health Organization (WHO), ICD-10 Version: 2016. Available at: https://icd.who.int/browse10/2016/en\#!/H55-H59 Accessed April 28, 2019.

7. İdil ŞA, Çalışkan D, İdil NB. Development and validation of the Turkish version of the MNREAD visual acuity charts. Turk J Med Sci. 2011;41: 565-570.

8. Silver J. Low vision aids in the management of visual handicap. Ophthalmic Physiol Opt. 1976; 31: 47-87.

9. Khanal S, Pokharel A, Kandel H. Visual deficits in Nepalese patients with oculocutaneous albinism. J Optom. 2016; 9: 102-109.

10. Schulze SM, Kumar N, Bohrmann D, Msukwa G, Kalua K, Kayange P, et al. Refractive errors, visual impairment, and the use of low-vision devices in albinism in Malawi. Graefes Arch Clin Exp Ophthalmol. 2015; 253: 655-661.

11. Eballe AO, Mvogo CE, Noche C, Zoua MEA, Dohvoma AV. Refractive errors in patients diagnosed with complete oculo cutaneous Albinism. Clin Ophthalmol. 2013; 1491-1495.

12. Wildsoet CF, Oswald PJ, Clark S. Albinism: its implications for refractive development. Invest Ophthalmol Vis Sci. 2000; 41: 1-7.

13. Yaman A, Berk AT. Clinical Features of patients with albinism and their correlation with visual acuity.Turkiye Klinikleri J Ophthalmol. 2008; 17: 161167.

14. Loshin DS, Browning RA. Contrast sensitivity in albinotic patients. Am J Optom Physiol Opt. 1983; 60: 158-166.

15. Karlen E, Milestad L, Pansell T. Accommodation and near visual function in children with albinism. Acta Ophthalmol. 2019;97(6):14040

16. Collins B, Silver J. Recent experiences in the management of visual impairment in albinism. Ophthalmic Genet. 1990; 11: 225-228.

17. Abner G, Lahm E. Implementation of Assistive Technology with Students Who Are Visually Impaired: Teachers' Readiness. J Vis Impair Blind. 2002; 96: 98 105.

18. Gothwal VK, Thomas R, Crossland M, Bharani S, Sharma S, Unwin H, et al. Randomized Trial of Tablet Computers for Education and Learning in Children and Young People with Low Vision. Optom Vis Sci. 2018; 95: 873-882. 
19. Bihter PP, Hurt JD. CPF-550 versus C-Lite: a comparison study. J Am Optometric Assoc. 1988; 59:623-628.

20. Langagergaard U, Ganer HJ, Baggesen K. Agerelated macular degeneration: filter lenses help in certain situations. Acta Ophthalmol Scand. 2003; 81: 455-458.

21. Leguire LE, Suh S. Effect of light filters on contrastsensitivity function in normal and retinal degeneration subjects. Ophthalmic Physiol Opt. 1993; 13: $124-128$.
22. Rosenblum YZ, Zak PP, Ostrovsky MA, Smolyaninova IL, Bora EV, Dyadina UV, et al. Spectral filters in low-vision correction. Ophthalmic Physiol Opt 2000;20:335-341.

\section{Author's Designation and Contribution}

Dr. Deniz Altınbay; Consultant: Research design, Data collection, Manuscript writing, Final review

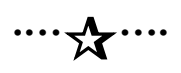

